\title{
Catheter induced spasm in aortocoronary vein grafts
}

\author{
JACQUELINE HEIJMAN, MAMDOUH EL GAMAL, ROLF MICHELS \\ From the Department of Cardiology, Catharina Hospital, Eindhoven, The Netherlands
}

SUMMARY Catheter induced spasm in venous bypass grafts was observed in two patients. In the first, it resolved 10 minutes after intravenous administration of $100 \mu \mathrm{g}$ glyceryl trinitrate and $0.2 \mathrm{mg}$ nifedipine. The second patient showed what was presumably spasm during angiography, for when the graft was visualised six weeks later, after receiving $10 \mathrm{mg}$ nifedipine and $0.5 \mathrm{mg}$ glyceryl trinitrate sublingually, the narrowed segment seen at the initial examination had disappeared. Our observation that spasm can occur in vein grafts and can be relieved by glyceryl trinitrate and nifedipine may have therapeutic consequences.

Although spasm in vein grafts after coronary bypass surgery has been sporadically observed, its occurrence is not yet widely recognised..$^{1-3}$ This report describes two cases of catheter induced spasm in bypass grafts.

\section{Case 1}

A 52 year old white man underwent coronary angiography in May 1980 because of severe angina pectoris. The left main coronary artery was totally occluded. The right coronary artery was normal and supplied collaterals to the left coronary artery. In June 1980, he underwent coronary revascularisation. A retroaortic saphenous vein graft was anastomosed to the left anterior descending artery. The circumflex branches were small and could not be revascularised. In January 1981, the patient had recurrence of angina pectoris. When investigated, severe ostial stenosis of the graft was found. Distal to the stenosis the graft appeared normal, and the anastomosis to the left anterior descending artery was intact. We decided to dilate the stenosis by percutaneous transluminal angioplasty. After successful dilatation of the ostium, control angiography disclosed a long narrowed segment in the middle of the vein (Fig. 1A). The patient did not complain of chest pain, and there were no electrocardiographic changes. Ten minutes after injecting $100 \mu \mathrm{g}$ glyceryl trinitrate and $0.2 \mathrm{mg}$ nifedipine in the pulmonary artery repeat angiography was performed. The narrowed segment in the vein had disappeared (Fig. 1B). When we dilated the ostium stenosis once more, the narrowing in the middle of the graft recurred and again disappeared after

Accepted for publication 31 August 1982 administration of glyceryl trinitrate and nifedipine.

\section{Case 2}

A 54 year old white man had angina pectoris, and coronary angiography in March 1978 disclosed total occlusion of the right coronary artery, and severe stenosis of the left anterior descending artery and the atrioventricular sulcus branch of the circumflex artery. He underwent coronary bypass surgery in June 1978, and received three aortocoronary saphenous vein grafts, to the left anterior descending artery, the atrioventricular sulcus branch of the circumflex artery, and the right coronary artery. He had no recurrence of angina pectoris after operation. Routine coronary and graft angiography was performed in March 1981. All three grafts were visualised. The graft to the right coronary artery appeared severely narrowed, just distal to the catheter tip near the aortic anastomosis (Fig. 2A). In spite of the absence of angina, we decided to dilate the stenosis by percutaneous transluminal angioplasty, before the graft eventually occluded. Six weeks later, when angioplasty was planned, the graft to the right coronary artery was visualised, but on this occasion minimal stenosis was found (Fig. 2B).

\section{Discussion}

Catheter induced spasm in coronary arteries during angiography is a well recognised entity. It is caused by mechanical irritation that triggers a myogenic reflex. It is relieved by sublingual administration of glyceryl trinitrate which also greatly reduces its incidence if given immediately before coronary angiography. 

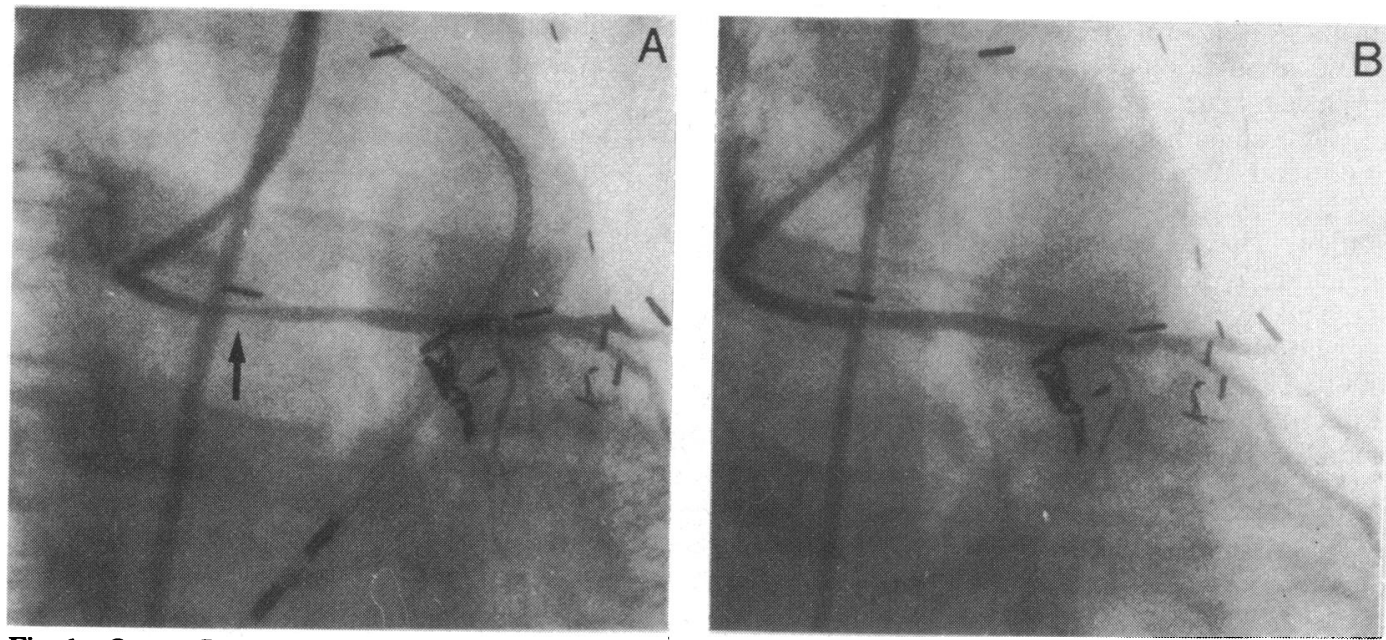

Fig. 1 Case 1. Retroaortic graft to the left anterior descending coronary artery, showing a long narrowed segment in the middle of the vein $(A)$. Ten minutes after administration of glyceryl trinitrate and nifedipine intravenously, the narrowing in the middle of the graft has disappeared (B).

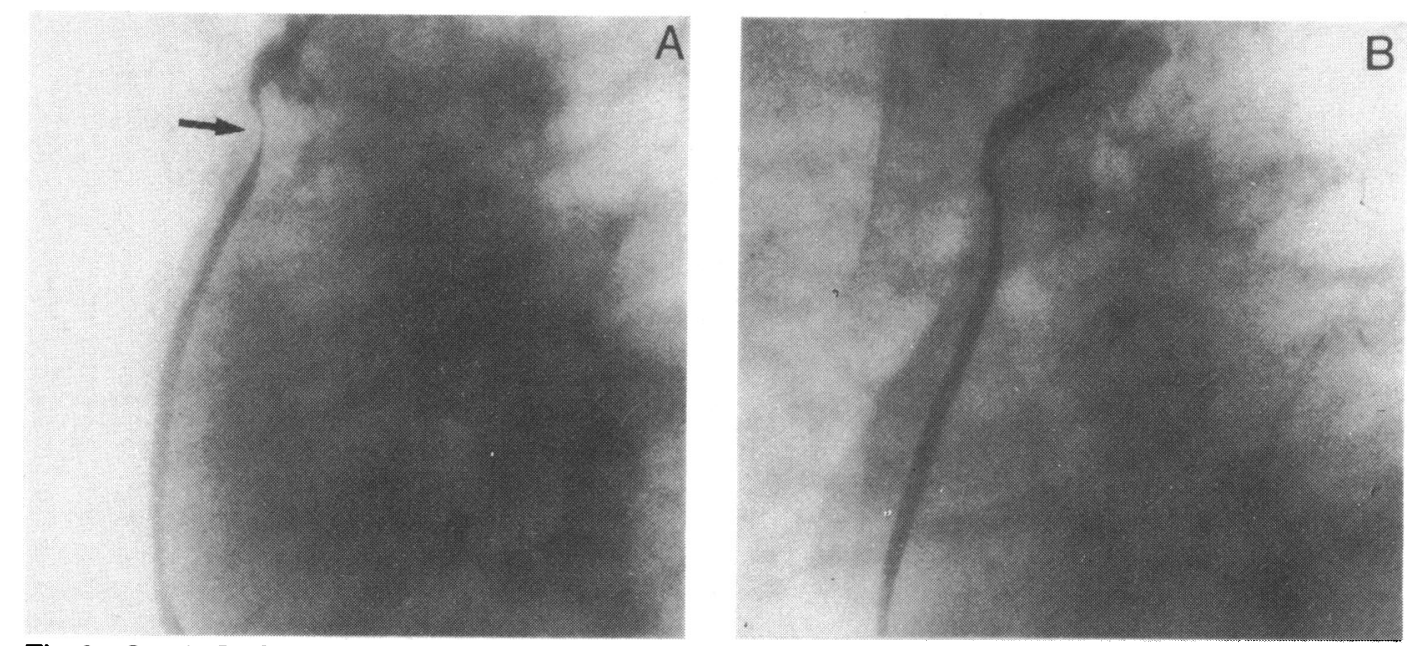

Fig. 2 Case 2. Graft to the right coronary artery showing severe narrowing just distal to the catheter tip $(A)$. The same graft visualised six weeks later after the administration of isosorbide dinitrate, glyceryl trinitrate, and nifedipine (B).

Our two cases show a similar phenomenon but in vein grafts, in which the occurrence of spasm is not widely recognized. It occurred in both cases during catheterisation and was related to catheter manipulation in the graft.

In the first case spasm was provoked twice by the balloon dilatation catheter and resolved each time after glyceryl trinitrate and nifedipine were injected intravenously.

In the second case, there was an interval of six weeks between the initial catheterisation at which severe narrowing of the graft was found, and the repeat angiography which did not show a narrowed segment. One can doubt whether the narrowing seen during the first angiogram was caused by spasm but its shape and location, just distal to the catheter tip, closely resembled catheter induced spasm in coronary arteries.

It is important to note that all candidates for angioplasty in our institution receive nifedipine and glyceryl trinitrate routinely before the procedure, in order to avoid spasm. Retrospectively, catheter induced spasm must have been responsible for the narrowing seen at the first catheterisation but the administration of glyceryl trinitrate, isosorbide dinitrate, and nifedipine before the repeat angiogram 
probably prevented its recurrence.

These observations clearly show that spasm can occur in vein grafts. This implies that some vein grafts have viable smooth muscle cells.

Spray and Roberts ${ }^{4}$ examined 65 venous bypass grafts in 38 patients who died two to 72 months after operation. The general experience at microscopical examination is that grafts become stiff fibrous conduits. This is a result of fibrous subendothelial thickening and fibrosis of the media.

In one 19 month old graft they observed little intimal thickening, but there were large amounts of subendothelial cells, resembling smooth muscle cells. This may have been the case in our second patient, who had spasm three years after coronary artery bypass surgery.

Spasm of vein grafts in our patients was catheter induced. If spasm could also occur spontaneously, it may then possibly play a role in the development of postoperative angina pectoris and graft closure.

Whether patients would benefit from the administration of glyceryl trinitrate, nitrates, or calcium antagonists during or after aortocoronary bypass surgery requires further investigation.

We would like to thank Mr LM van Gelder for his help in preparing this manuscript.

\section{References}

1 Victor MF, Kimbiris D, Iskandrian AS, et al. Spasm of a saphenous vein bypass graft. Chest 1981; 80: 413-5.

2 Baduini G, Marra S, Angelino PF. Sudden occlusion of a saphenous vein bypass graft relieved by direct injection of nitroglycerin. Cathet Cardiovasc Diagn 1981; 7: 87-95.

3 Walinsky P. Angiographic documentation of spontaneous spasm of saphenous vein coronary artery bypass graft. Am Heart $f$ 1982; 103: 290-2.

4 Spray TL, Roberts WC. Changes in saphenous veins used as aortocoronary bypass grafts. Am Hearn $\mathcal{f}$ 1977; 94: 500-16.

Requests for reprints to Dr Mamdouh El Gamal, Department of Cardiology, Catharina Hospital, Michelangelolaan 2, 5623 EJ Eindhoven, The Netherlands. 